\title{
Once upon an invisible TIME: On Frequentative Phrases in Chinese
}

\author{
Wei-Wen Roger Liao \\ Institute of Linguistics, Academia Sinica
}

\begin{abstract}
In view of Kayne's (2014) analysis, the English expressions of once, twice, and \#-times are compared with the corresponding Chinese expression, \#-ci. This paper shows that data from Chinese not only support Kayne's analysis that treats the silent TIME as classifier, but they also suggest that the frequentative phrase may involve a silent NP and/or PP. The latter provides some possible modifications to Kayne's original analysis of the suffix $-c e$.
\end{abstract}

\section{Keywords}

silent element, durative/frequentative phrases, classifiers, Chinese syntax

Studies in Chinese Linguistics, Volume 36, Number 1, 2015, 21-33 DOI: 10.1515/scl-2015-0002 (C)2015 by T.T. Ng Chinese Language Research Centre, Institute of Chinese Studies, The Chinese University of Hong Kong 


\section{Introduction}

Kayne (2014) argues that once and twice in English are Prepositional Phrases (PP), where on- and $t w$ - are related to the numeric roots one and $t w o$, and the suffix $-c e$ is taken to be a postposition that heads the PP. Moreover, the parallel between examples (1) and (2) suggests that on-ce contains a silent counterpart of time (namely, a silent TIME), which Kayne assumes to be a (singular) classifier, reminiscent of the silent NUMBER in a few questions (Kayne 2007), as in (3): ${ }^{1}$

(1) We were young once.

(2) We were young at one time.

(3) a. a few NUMBER $R_{\text {singular }}$ questions

b. $\left[_{\mathrm{PP}}\left[\mathrm{on}(\mathrm{e})-\mathrm{TIME}_{\text {singular }}\right]-\mathrm{ce}\right]$

In this squib, frequentative phrases (FrqP) in (Mandarin) Chinese are discussed. ${ }^{2}$ I compare them with English ones under Kayne's analysis.

\section{Two types of frequentative phrases in Chinese}

Chinese does not have distinct forms for 'one time' and 'two times' (like once and twice in English), and all frequentative phrases are regularly expressed by the sequence \#-ci '\#-time/occasion' (where \# is a numeral), which looks very much like a numeral-classifier phrase, as in (4):
a. Women qu-guo yi/liang/san/si...-ci Beijing. we go-Asp one/two/three/four...-time Beijing 'We went to Beijing once/twice/three times/four times...'
b. Women mai-le yi/liang/san/si... -ben shu. Women buy-Asp one/two/three/four...-Cl book 'We bought one/two/three/four books.'

Interestingly, the frequentative phrase may also occur in the preverbal position, in which case, it looks less like a numeral-classifier phrase, as in (5):

a. Zhangsan yi-ci dasi-le qi-zhi. Zhangsan one-time kill-Asp seven-Cl

'Zhangsan killed seven at one time/strike.'

b. Zhangsan guji san-ci keyi xie-wan ta-de baogao. Zhangsan estimate three-time can write-finish is paper 'Zhangsan estimated that he can finish his paper in three times.'

1 I follow Kayne's convention in representing silent elements with capital letters.

2 Unless otherwise specified, Chinese will refer to the variety of Mandarin Chinese in this paper. 
In the following sections, I shall argue that both types of FrqPs are actually numeral-classifier (Num-CL) phrases that may involve additional silent NPs and/ or silent PPs, which immediately recalls Kayne's analysis of the English words once and twice. I will return to the English -ce in Section 2.3.

\subsection{FrqP and classifier}

The idea of treating FrqP as Num-CL (rather than a simple noun phrase) can be supported by the following facts. First, the nominal element $-c i$ 'time' cannot be topped by the default classifier ge (or any other classifiers), indicating that it is not a substantive noun but a classifier, comparable to the classifier tian 'day', as in (6), and is in contrast to the more 'nounish' yue 'month', as in (7) (Tang 2005): ${ }^{3}$

$$
\begin{aligned}
& \text { a. yi }(* \text { ge }) \text { ci } \quad[c i=+ \text { classifier, }- \text { noun }] \\
& \text { 'once/one time' } \\
& \text { b. yi }(* \text { ge }) \text { tian } \quad[\text { tian }=+ \text { classifier, }- \text { noun }] \\
& \text { one } \mathrm{Cl} \text { day } \\
& \text { 'one day' } \\
& \text { (7) yi } *(\mathrm{ge}) \quad \text { yue } \quad[y u e=- \text { classifier, }+ \text { noun }] \\
& \text { one } \mathrm{Cl} \text { month } \\
& \text { 'a month' }
\end{aligned}
$$

Second, as typical substantive nouns cannot combine with numerals directly, the fact that $-c i$ can be directly preceded by numerals provides another piece of evidence that $-c i$ should be treated as a classifier. ${ }^{4}$ An anonymous reviewer raises a concern regarding the first test, claiming that many substantive nouns cannot be combined with the default classifier ge, yet they are nouns, not classifiers. However, substantive nouns must be counted with classifiers in Chinese (it does not matter whether the classifier is ge or other classifiers), but one simply is not able to find a classifier for $-c i$.

Third, on a par with classifiers, $c i$ can undergo reduplication, as in (8), again in contrast to the noun in $(8 \mathrm{c})$ :
a. yi ci-ci one time-time 'once after another'
$\begin{array}{lll}\text { c. }{ }^{*} \text { yi } & \text { (ge) } & \text { yue-yue } \\ \text { one } & \mathrm{Cl} & \text { month-month }\end{array}$
b. yi bei-bei
one cup-cup
'one cup after another'

3 Note that it is possible to have yi ge cishu (one $\mathrm{Cl}$ time) 'one round', which is quite different from $y i$ - $c i$ 'once' in that it is ungrammatical to say (i), in parallel to (4a):
$\begin{array}{ll}* \text { (i) } & \text { qu-guo } \\ \text { I } & \text { go-Asp }\end{array}$ $\begin{array}{ll}\text { yi } & \text { ge } \\ \text { one } & \mathrm{Cl}\end{array}$ cishu de Beijing. Beijing
4 I owe this point to an anonymous SCL reviewer. 
Fourth, from the behavior of DE, we have another piece of evidence that FrqP behaves on a par with Num-CL (rather than modifiers). In Chinese, DE is obligatory under NP-fronting when it is a modifier-DE; on the other hand, DE cannot appear if it is a classifier-DE (Li 2013, Tang 2005). This contrast is illustrated in (9):5

a. modifier-DE: obligatory under NP-fronting

Niunai, Zhangsan he-le bu-xinxian*(-de)
milk Zhangsan drink-Asp not-fresh-DE
'Zhangsan had some spoiled milk.'
. classifier-DE: illegitimate under NP-fronting
Niunai, Zhangsan he-le wu-ping( ${ }^{*}$-de $)^{6}$
milk, Zhangsan drink-Asp five-bottle
'Zhangsan had five bottles of milk.'

The following example shows that the FrqP behaves like classifier in that DE cannot appear when the noun is fronted:

$\begin{array}{llll}\text { Beijing, women } & \text { qu-guo } & \text { yi/liang/san/si...-ci } & (* \text { de }) . \\ \text { Beijing we } & \text { go-Asp } & \text { one/two/three/four...-time } & \text { DE } \\ \text { 'We went to Beijing once/twice/three times/four times...' } & \end{array}$

We can therefore safely conclude that FrqP is a type of Num-CL phrase in Chinese, and the noun after the FrqP is a noun classified by the Num-CL, as in (11), in which the FrqP has the following structure: ${ }^{7}$

5 As generally assumed, only two types of objects are permitted when two syntactic objects merge: (i) adjuncts/modifier-X(P) (by adjunction) and (ii) head-complement (by substitution) (Kayne 1994, Chomsky 1995, among many others).

6 With DE, the sentence may have a meaning where five-bottle is a modifier of milk (i.e., a five-pack milk).

7 One anonymous reviewer points out the following counterexample, where the fronted object is a DP, not simply an NP:

$\begin{array}{llllllll}\text { (i) Zhe } & \text { yi } & \text { ben } & \text { shu, } & \text { wo } & \text { kan-le } & \text { san } & \text { ci } \\ & \text { this } & \text { one } & \text { Cl } & \text { book } & \text { I } & \text { read-Asp } & \text { three }\end{array}$

'This book, I read it for three times.'

It is possible, however, that a classifier may take DP as its complement, as discussed in Liao and Wang (2011):
(ii) Wo
kan-guo san ci
[DP $\quad$ zhe
ben shu].
I read-Asp three time
this
$\mathrm{Cl}$ book
'I read this book for three times.'

As Liao and Wang observes, it is not possible to omit the demonstrative of the following DP:
(iii) *Wo
kan-guo san
ci
[yi
ben
shu].

I read-Asp three time

Likewise, the following sentence is ungrammatical:
(iv) *Yi
ben
shu,
I
kan-guo san
ci
one
$\mathrm{Cl}$
book I
read-Asp three
time 
(11)

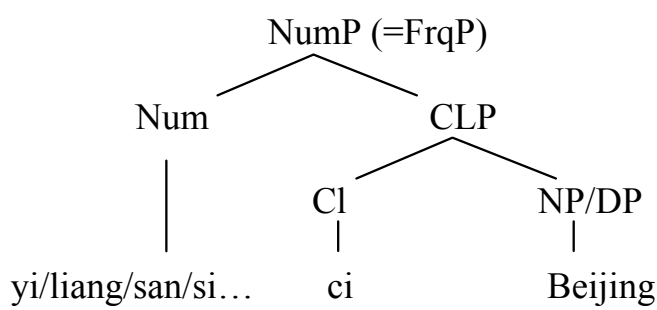

The proposal that yi ci Beijing forms a single constituent can be evidenced by the fact that it may undergo lian...dou focalization as a unit, as shown in (12):
Zhangsan lian [yi ci Beijing] dou mei qu-guo [yi ei Beijing]
Zhangsan even one time Beijing all not go-Asp
'Zhangsan has never been to Beijing, not even once.'

Therefore, instead of treating the durative phrase as an adverb (forms constituent with VP), evidence shows that it forms constituent with NP/DP. The fact is accounted for if the durative phrase is treated as numeral-classifier in Chinese. ${ }^{8}$

However, this analysis is faced with some potential challenges. Specifically, FrqP can be used in the unergative construction, where no object NP is observed, as in (13):
Zhangsan ku-le san-ci.
Zhangsan cry-Asp three-time
'Zhangsan cried for three times.'

8 An anonymous reviewer argues that (11) cannot explain why the frequentative-NP cannot be topicalized or be the $b a-\mathrm{NP}$, and the ungrammaticalities of (i) and (ii) suggest that [yi ci Beijing] is not a constituent:
(i) *Yi ci Beijing, women qu-guo. one time Beijing we go-Asp
(ii) *Zhangsan ba yi ci Beijing qu-guo. Zhangsan BA one time Beijing go-Asp
'[intended:] We have been to Beijing once.'

I believe that the sentences are ruled out for an independent reason that the topicalized NP/DP and $b a$-NP must be specific/generic (see Liu 1997 and the references therein). If the topicalized BA-NP is specific, the sentences are very much improved:
(iii) Zhe yi ci Beijing, wo dai
this one time Beijing I stay 'I stay in Beijing for the longest time this time.'

(iv) Ta ba zhe ji nian shu nian dao nali qu le?
'He has wasted his several years of education. (lit. Where does he put his several years of education?' 
This problem can be circumvented if we assume the theory of Hale and Keyser (2002), who argue that unergative verbs like dance, cry, dream, etc., actually involve empty cognate nouns at the level of l-syntax, represented as follows (Hale and Keyser 2002: 93):

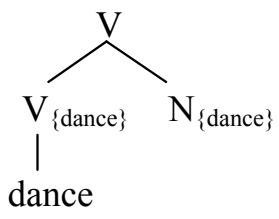

In this sense, examples like (13) may also contain an empty cognate N (or NP) projected from the l-syntax of such verbs, which is classified by the Num-CL (or the FrqP), as in (15): ${ }^{9}$
Zhangsan ku-le san-ci $\mathrm{N}_{\{\text {cry\} }}$.
Zhangsan cry-Asp three-time
'Zhangsan cried for three times.'

Another puzzle is from the preverbal FrqPs in (5). If we analyze them as NumCL phrases as well, they would also need to contain silent NPs (since a classifier requires a noun to classify). Let's assume that these expressions also contain a silent NP, meaning EVENT or OCCASION, similar to the English expressions like on one TIME occasion (if we take TIME to be the counterpart of the frequentative classifier $-c i$ ). This also suggests that once and twice in English may also take a silent NP, in addition to the silent classifier TIME: [[[one-TIME] NP] -ce].

Taking TIME as classifier in English may also explain why it is only compatible with the numeral one and two. In classifier languages, we do find similar restriction between numerals and classifiers (but not between numerals and nouns). For example, in Chinese, the classifier xie and dian is limited to yi 'one' (Chao 1968, Liao and Vergnaud 2013, Sio 2006) (In some varieties of Mandarin Chinese,

9 The analysis also recalls the syntax-semantic mismatch of the Chinese durative phrase in Huang (1997), where the N-to-V raising in Huang might be viewed as a chain-formation in the 1-syntax. 
however, liang-xie 'two-XIE' also seems possible). ${ }^{10}$ This also points out to a very important distinction between classifier TIME and substantive time, where the former is restricted to the numeral one and $t w o$, and the latter is immune from such a restriction (it could be argued that one time and two/three... times may also involve silent classifier NUMBER, i.e., [[two NUMBER] times], in the sense of Kayne (2007), and the silent classifier NUMBER does not pose any selectional restriction on numerals).

A related question considers the semantic functions of the durative/frequentative classifiers. ${ }^{11}$ Unlike typical classifiers, the durative/frequentative classifiers do not directly measure the "quantities of objects", but they measure the "quantities of events". That is to say, there will be a syntax-semantic mismatch if the durative/ frequentative phrases are really classifiers. In a way, the mismatch is reminiscent of Huang's (1997) famous example in the following:
Zhangsan
mai-le [yi-nian de
$\mathrm{yu}$.
Zhangsan sell-Asp one-yearDE fish
'Zhangsan has been selling fish for one year.'

In (16), the existence of de signals that yi-nian is part of the NP-constituent, although the durative phrase somehow measures the length of the fish-selling event. The syntax-semantic mismatch, however, is not specific in Chinese. Larson (2003) observes the following examples in English:

10 The following passage is from Lao Can Youji 老殘遊記 'The Travels of Lao Can':

(i) 老殘連忙起身讓坐, 說: 我因為這兩些天困於酒食, 覺得怪淢的慌. (老殘遊記第一回 Lao Can lianmang qishen rang zuo, shuo: "wo yinwei zhe liang-xie Lao Can in.a.hurry stand.upyield seat say I because this two-XIE tian kun yu jiushi, juede guai ni de huang." day stuck by food.and.drink feel very tired DE very "Lao Can stood up politely in a hurry, and said 'I have indulged in drinking and eating for a few days and felt rather exhausted."

A simple Google search of “兩些” on the Internet also returns some interesting examples:

(ii) 前两些天看了房子, 折扣真是太少了(http://sh.focus.cn/group/group_tag_list.php?tag_id=6557)
Qian liang-xie tian kan-le
fangzi, zhekou zhen shi
tai shao le. Past two-XIE day look-Asp house discount really is too little SFP 'For the past few days, we have looked at some houses, but the discounts are really too small.'

(iii) 主站的同事找來了日本Sony的Nicolas Doucet為我們講解這兩些產品怎樣運作
Zhu-zhan de tongshi zhaolai-le Riben Sony de Nicolas Doucet master-station DE colleague find-Asp Japan Sony DE Nicolas Doucet wei women jiangjie zhe liang-xie canping zenyang yunzuo. for us demonstrate this two-XIE products how operate
'Our colleagues in the master station invited Nicolas Doucet from Sony in Japan to demonstrate how to operate these few products.'
(http://cn.engadget.com/2013/06/12/lets-take-a-closer-look-at-the-playstation-4-dualshock-4-and-p/)
However, we are not able to exclude the possibility that these examples contain typographic errors.
11 I would like to thank an anonymous SCL reviewer for raising the question. 
(17) a. get [two hours of sleep] = 'sleep for two hours'

b. get [two feet of rope]

The same syntax-semantic mismatch is found in (17a), where two hours behaves like a 'classifier' on a par with two feet in (17b), yet it is able to behave like a VPmodifier at LF. ${ }^{12}$ Larson's solution toward such mismatches is to employ the event argument in the sense of Davidson (1967), and Larson proposes that "measurement (M)" is a higher-ordered predicate over the whole proposition, and therefore, just like the object measurement in (18), one can directly measure the event argument, as in (19) (both from Larson 2003):

(18) a. Mary bought two spoonfuls of sugar.

b. $M_{\text {spoonfuls }}[$ the $x: \operatorname{sugar}(x) \& \operatorname{buy}($ Mary, $x)]=2$

'Measured in spoonfuls, the amount of sugar bought by Mary is 2.'

(19) a. Mary observed two hours of walking.

b. $\mathrm{M}_{\text {hours }}[$ the e: walking(e) \& observe(Mary, e)] $=2$

'Measured in hours, the amount of walking observed by Mary is 2.'

In the sense of Larson (2003), then, the durative/frequentative classifier in Chinese may also measure the event argument in VP, despite it being a nominal classifier in syntax:
a. Lisi mai-le yi-nian (de) yu.
Lisi sell-Asp one-year DE fish
'Lisi sold fish for a year.'
b. $M_{\text {year }}[$ the e: selling(e) \& Agent (Lisi, e) \& Participant (fish, e)]=1

\subsection{FrqP and the silent PP}

Lin (2011) observes that the bare durative phrases tend to have a completive meaning in the preverbal positions, while they have a durative meaning in the postverbal positions:
a. Zhangsan san-tian xie-le shu. [completive] Zhangsan three-day write-Asp book 'Zhangsan finished a/the book in three days.'
b. Zhangsan xie-le san-tian shu. [durative] Zhangsan write-Asp three-day book 'Zhangsan wrote books for three days.'

12 The mismatch is also found in transitive verbs in English:

(i) You hear some nice harmonies and very good voices [sing two hours of songs].

(http://www.floridatoday.com/story/entertainment/arts/pam-harbaugh/2014/10/29/ellen-pavlakosexhibits-fifth-avenue-art-gallery/18132539/) 
The same difference can also be observed in the FrqPs. Therefore, in (5) and (21a), the FrqP "delimits" the occurrence of the event (as the completive phrase delimits the event), and in (4) and (21b), the FrqP "measures" the occurrence of the event (as the durative phrase measures the duration of the event) (Krifka 1988). This shows that instead of using different prepositions to elicit different readings as in English, Chinese employs a strategy that distinguishes the contrast by syntactic positions. It is also plausible to assume that the preverbal FrqP contains a silent preposition of the completive IN-type (cf. Emonds 1987, McCawley 1988), and such a preposition is structurally licensed in the preverbal position: ${ }^{13}$

\begin{tabular}{|c|c|c|}
\hline $\begin{array}{l}\text { a. Zhangsan [IN } \\
\text { Zhangsan }\end{array}$ & $\begin{array}{ll}\text { san-tian] } & \text { xie-le } \\
\text { three-day } & \text { write-Asp }\end{array}$ & $\begin{array}{l}\text { yi-ben } \\
\text { one-Cl }\end{array}$ \\
\hline
\end{tabular}

Concluding from our discussion above, the underlying structure of the FrqP in Chinese can be illustrated in (23), where the preposition is limited to the IN-type, and the NP may be a silent OCCASION/EVENT, or it can be an NP classified by the classifier $-c i$ :

$$
\left[_{\mathrm{PP}}(\mathrm{IN}) \ldots\left[_{\mathrm{NumP}} \# \quad\left[\mathrm{CLP}_{\mathrm{C}}-\mathrm{ci}[\mathrm{NP}]\right]\right]\right]
$$

One issue arises regarding the projection of the preposition. The preposition is projected only when it occupies a preverbal position, where no Case is assigned by the structure. This is reminiscent of the Case Filter (Chomsky and Lasnik 1977, Vergnaud 1985), and the preposition does not appear when the verb is able to assign a structural Case to the Num-CL NP (or possibly a DP) when it occurs in the object position.

\subsection{The suffix - ce and preposition}

Coming back to the English expressions once and twice, a similar question can be raised of whether they are always projected to PPs. In cases comparable to Chinese preverbal FrqPs and English adverbial phrase in one/two times, the projection of P seems justified. In cases comparable to Chinese post-verbal FrqPs, however, the projection of $\mathrm{P}$ looks unmotivated, as in (24), where the corresponding expression three times does not allow a preposition either:

(24) John ate [(*for) twice/three times the amount of food] last night.

This leads to a question why the preposition is needed in the preverbal nonargument position. The fact that prepositions are not required in "argument

13 One plausible overt realization of the silent adposition might be the postposition -nei 'within':

(i)Zhangsan [san-tian-nei] xie-wan yi-ben shu.

Zhangsan three-day-within write-finish one-Cl book

'Zhangsan finished a book in three days.' 
positions" may suggest that this problem is related to Case licensing. That is, once and twice must occur in a Case-licensed position, and a major difference between once and twice, and the regular expressions (\#-times) lies in the ability to self-contain a Case-licensor. That is, once and twice can license their own Cases when no other licensors are present. In a similar vein to Kayne's analysis, we may assume that this is the role played by the suffix -ce. In a minimalist term, which slightly departs from Kayne's original analysis, we may describe such a rule by assuming that the suffix -ce contains a unvalued K-feature that must be locally licensed (perhaps -ce heads a KP below PP, as suggested by Kayne (2014) in a footnote), and such a local licensing condition can be done either by head-raising or by agreement with a local head (be it a preposition or a verb). The mechanisms are illustrated as follows:

(25) Head-raising of -ce to $\mathrm{P}$ (when $\mathrm{P}$ is not occupied by an overt preposition)

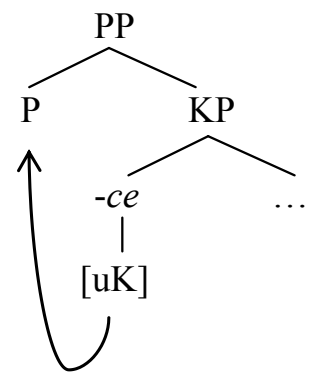

(26) Agreement of -ce by V or P (when P is occupied by an overt preposition) $)^{14}$

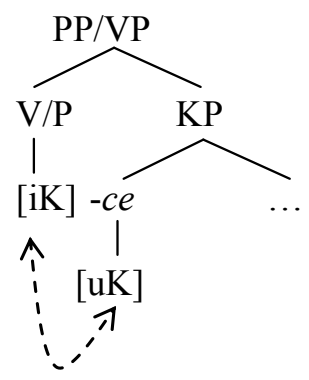

This mechanism (which is reminiscent of the mechanism of satisfying the EPP feature on $\mathrm{T}$ through subject raising or through merger of an expletive) then allows us to account for why -ce sometimes seems to head a PP (as argued in Kayne), and

14 It has been suggested in the Strong Minimalist Thesis that Case be reduced to other features (or feature-bundles), and that the Accusative Case is valued by little v (Chomsky 1995, 2001). The analysis presented here can be adjusted accordingly. 
why it sometimes does not. The analysis also provides an alternative account for why once cannot occur as a relative head, as observed in Kayne (2014):

(27) They told us about the $*^{*}$ once $/{ }^{\circ k}$ one time they thought they were really in danger.

The reason is that once, but not one time, must occur in a locally Case-licensed position (due to the presence of $-c e$ ), and the external determiner in the relative clause (Kayne 1994) fails to license/assign a proper Case to once. ${ }^{15}$

\section{Conclusion}

Guided by the provocative analysis in Kayne (2014), I have compared the English expressions, once/twice and \#-times, with the Chinese ones, (\#-ci). The findings suggest that these expressions share a universal structure that involves numeralclassifier phrases, and may also involve empty NPs and/or PPs. The observation regarding Chinese PPs also provides some modification to Kayne's (2014) original analysis of $-c e$.

\section{Acknowledgments}

I am in debt to three anonymous SCL reviewers for their helpful reviews and comments. I thank W.-C. Sam Jheng for the assistance in preparing the manuscript. I would also like to express my gratitude to the editor Prof. Tang Sze-Wing for inviting me to submit this commentary. All errors remain mine alone.

\section{References}

Chao, Yuen-Ren. 1968. A grammar of spoken Chinese. Berkeley: University of California Press.

Chomsky, Noam, and Howard Lasnik. 1977. Filters and control. Linguistic Inquiry 8. 425-504.

Chomsky, Noam. 1995. The minimalist program. Cambridge, MA: MIT Press.

Chomsky, Noam. 2001. Derivation by phase. In Michael Kenstowicz (ed.), Ken Hale: A life in language, 1-52. Cambridge, MA: MIT Press.

Davidson, Donald. 1967. The logical form of action sentences. In Nicholas Rescher (ed.), The logic of decision and action, 81-120. Pittsburgh: Pittsburgh University Press.

Emonds, Joseph Embley. 1987. The invisible category principle. Linguistic Inquiry 18(4). 613-632.

Hale, Kenneth \& Samuel Jay Keyser. 2002. Prolegomenon to a theory of argument structure. Cambridge, MA: MIT Press.

15 It should be noted that this once (or \% the once) is possible in English (Kayne 2014), where this is internal to the PP structure: $\left[_{\mathrm{PP}}\left[_{\mathrm{KP}}-c e\left[_{\mathrm{DP}}\right.\right.\right.$ this/the on(e)-]]]. On the other hand, in relative clauses, the determiner comes from external to the -ce phrase (assuming the analysis in Kayne 1994), and this results in the wrong structure: $*_{\mathrm{DP}}$ the $\left[_{\mathrm{KP}}-c e . ..\right]$, and $-c e$ must be locally licensed by a Caseassigning $[-\mathrm{N}]$ category. 
Huang, C.-T. James. 1997. On lexical structure and syntactic projection. Chinese Languages and Linguistics 3. 45-89.

Kayne, Richard. 1994. The antisymmetry of syntax. Cambridge,MA: MIT Press.

Kayne, Richard. 2007. Several, few and many. Lingua 117(5). 832-858.

Kayne, Richard. 2014. Once and twice. Studies in Chinese Linguistics 36(1).

Krifka, Manfred. 1988. The origin of telicity. In Susan Rothstein (ed.), Event and grammar, 197-235. Dordrecht: Kluwer.

Larson, Richard. 2003. Time and event measure. Philosophical Perspectives 17(1). 247-258.

Li, Yen-hui Audrey. 2013. P-insertion and ellipsis. Studies in Chinese Linguistics 34(2). 99-128.

Liao, Wei-wen Roger \& Jean-Roger Vergnaud. 2013. On merge-markers and nominal structures. In Katy McKinney-Bock \& Maria Luisa Zubizarreta (eds.), Primitive elements of grammatical theory: Papers by Jean-Roger Vergnaud and his collaborators, 237-273. New York : Routledge, Taylor \& Francis Group.

Liao, Wei-wen Roger \&Yuyun Iris Wang. 2011. Multiple-classifier constructions and nominal expressions in Chinese. Journal of East Asian Linguistics 20(2). 145168.

Lin, Jo-wang. 2011. Chinese durative and completive nps as polarity items. In JungHsing Chang (ed.), Language and cognition: Festschrift in honor of James H-Y. Tai on his 70th birthday, 345-362. Taipei: Crane.

Liu, Feng-Hsi. 1997. An aspectual analysis of ba. Journal of East Asian Linguistics 6. 51-99.

McCawley, James. 1988. Adverbial NPs: Bare or clad in see-through garb? Language 64: 583-590.

Sio, Joanna. 2006. Modification and reference in the Chinese nominal. Leiden: Leiden University dissertation.

Tang, Chin-Chen Jane. 2005. Nouns or classifiers: A non-movement analysis of classifiers in Chinese. Language and Linguistics 6(3). 431-472.

Vergnaud, Jean-Roger. 1985. Dependance et niveaux de representation en syntaxe. Amsterdam: John Benjamins.

Address: Institute of Linguistics, Academia Sinica, 128, Sec.2, Academia Rd. Nangang, Taipei 115, Taiwan.

Email: Iwwroger@gate.sinica.edu.tw

Received: July 8, 2014

Accepted: December 1, 2014 
消失的“時間”：談漢語的計次詞組

廖偉聞

中央研究院語言學研究所

提要

本文從 Kayne (2014) 提出的分析談起，比較漢語與英語的計次詞組。我們提出證 據指出計次詞組在漢語應該分析為量詞組，這呼應了 Kayne 提出的空成分 TIME 應 該分析為量詞的論點。本文進一步指出在某些環境下，這些量詞組應該也包含了空 的名詞與介詞。這些從漢語得到觀察與分析不但呼應了 Kayne 對英語的分析，也對 Kayne 原來的分析提供了一些可能的修改方向。

關鍵詞

無聲成分，時 / 次量詞組，量詞，漢語句法 